\title{
ANALYSIS OF MODE OF DELIVERY WITH VARIOUS INDUCTION TECHNIQUES IN TERTIARY CARE HOSPITAL AT RAYALASEMA REGIOZ
}

\section{Anita Ramesh Annaldasula.}

Associate professor, obstetrics \& Gynecology, Shanthiram Medical College, Nandyal, Kurnool, Andhra Pradesh, India.

\section{ABSTRACT}

Induction of labour (IOL) needs to be considered when the risk-benefit analysis indicates that delivering the
baby is a safer option for the baby, the mother, or both, rather than continuing the pregnancy, and when there
are no clear indications for caesarean section and no contraindications for vaginal delivery. In the span of one
year time we observed 200 deliveries outcome of term pregnancies subjected to various methods of induction
of labour was to evaluate the outcome of pregnancy at term by elective induction of labour in order to reduce
the cesarean section rate in Rayalasema region at Santhiram medical college and hospital. The results were
modified Bhishop's score were mean \pm SD $6.35 \pm 2.26$. In that Amniotomy (normal vaginal delivery $5 \%$ and
ceasarian $10 \%$ ), Cerviprime (normal vaginal delivery $5.5 \%$ and ceasarian $17.5 \%$ ), Foleys (normal vaginal delivery
2 and ceasarian $12.5 \%$ ), Misoprostol (normal vaginal delivery $2.5 \%$ and ceasarian $12.5 \%$ ), Oxytocin (normal
vaginal delivery $2.5 \%$ and ceasarian $15 \%$ ), Stripping (normal vaginal delivery $2.5 \%$ and ceasarian $12.5 \%$ ). We
also measured the Cardiac Tocograph after the induction in that Amniotomy (normal vaginal delivery $5 \%$ and
ceasarian $10 \%$ ), Cerviprime (normal vaginal delivery $5.5 \%$ and ceasarian $17.5 \%$ ), Foleys (normal vaginal delivery
2 and ceasarian $12.5 \%$ ), Misoprostol (normal vaginal delivery $2.5 \%$ and ceasarian $12.5 \%$ ), Oxytocin (normal
vaginal delivery $2.5 \%$ and ceasarian $15 \%$ ), and Stripping (normal vaginal delivery $2.5 \%$ and ceasarian $12.5 \%$ ),
fetal outcome $5 \%$ of fetal were admitted in the ICU with various complications. The Cerviprime can be considered
as safe, efficacious, cheap and mother and fetus friendly for the induction of labour.
KEY wORDS: Amniotomy, Cerviprime, Foleys, Misoprostol, Oxytocin, and Stripping.

Address for correspondence: Anita Ramesh Annaldasula, Associate professor, obstetrics \& Gynecology, Shanthiram Medical College, Nandyal, Kurnool, Andhra Pradesh, India.

E-Mail: anitasreekanth123@gmail.com

\begin{tabular}{|c|c|c|}
\hline \multicolumn{3}{|c|}{ Online Access and Article Informtaion } \\
\hline \multirow{2}{*}{ Quick Response code } & \multicolumn{2}{|c|}{$\begin{array}{l}\text { International Journal of Integrative Medical Sciences } \\
\text { www.imedsciences.com }\end{array}$} \\
\hline & $\begin{array}{l}\text { Received: 17-12-2017 } \\
\text { Reviewed: 17-12-2017 }\end{array}$ & $\begin{array}{l}\text { Accepted: 08-01-2018 } \\
\text { Published: 31-01-2018 }\end{array}$ \\
\hline Source of Funding: Self & \multicolumn{2}{|c|}{ Conflicts of interest: None } \\
\hline
\end{tabular}

\section{BACKGROUND}

Induction of labour means initiation of uterine contractions (after the period of viability) by any method (medical, surgical or combined) for the purpose of vaginal delivery. Induction of labour is the stimulation of uterine contraction prior to the onset of spontaneous labour. It is an obstetric intervention that should be used when elective birth will be beneficial to mother and baby. As per the WHO global survey the rate of labor induction have risen to reach $20 \%$ of all labors in developed countries, they included 24 countries and nearly 300,000 deliveries, showed that $9.6 \%$ of deliveries by labor induced. The survey found that ranging from $1.4 \%$ in Niger to $35.5 \%$ in Sri Lanka, 6.6\% was reported in Maidu-guri, United States; the rate varies from 9.5 to 33.7 percent of all pregnancies annually [1].

Induction of labour ( $\mathrm{IOL}$ ) needs to be considered when the risk-benefit analysis indicates that delivering the baby is a safer option for the baby, the mother, or both, rather than continuing the 
pregnancy, and when there are no clear indications for caesarean section and no contraindications for vaginal delivery. Post-term gestation, pre-labour rupture of membranes (at term and preterm) and fetal growth restriction are the leading indications for IOL [2]. Other situations in which IOL may be indicated include medical disorders (such as hypertensive disorders of pregnancy), suspected fetal macrosomia, intrauterine fetal death, multiple gestations, chorioamnionitis and even maternal request [2-4].

Normal pregnancy lasts about 40 weeks from the start of the women last menstrual period, but anything from 37-42 weeks is considered as being within the normal range. Births before 37 weeks are considered preterm because these babies often have breathing difficulties and other problems as some of their organs are not fully matured. Births after 42 weeks seem to carry slightly increased risk for the baby under associated with greater number of deaths or many of them can go into cesarean section.

No tests can tell if a baby would be better to be left in the womb or labour induced, so arbitrary time limits have been suggested. So this study is required to determine if induction of labour at a pre-specified time (at term) could reduce the risks for the baby. Induction of labour is nonspontaneous initiation of uterine contractions prior to their spontaneous onset leading to progressive effacement and dilation of cervix and delivery of the baby. This study is used to assess the various methods of induction of labour and their outcomes in lowering the cesarean section rate and to analyse the causes of prolonged labour, postpartum haemorrhage, and critically evaluate perinatal morbidity and mortality in our hospital.

\section{MATERIALS AND METHODS}

A prospective study presenting between September 2016 to September 2017 at Department of Obstetrics and Gynaecology at Santhiram medical college and hospital, Nandyal. A.P. with 200 antenatal women will be included in the present study. A detailed well informed consent was taken from all the subjects included in the present study. The study was approved by institutional ethical committee.
Inclusion Criteria: 1 . All term pregnancies beyond 37 weeks period of gestation, 2 . Cephalic presentation, 3 . Singleton live gestation, 4 . Intact membranes.

Exclusion Criteria: 1. Abnormal lie and malpresentation, 2. Cephalopelvic disproportion, 3. Pregnancy with congenital abnormalities 4. Previous uterine scar 5 . Abnormal fetal heart rate pattern before induction on NST 6. Ante-partum haemorrhage 7 . Known bronchial asthma patients.

Basic steps of examination in patients include: Explained about study and obtained written informed consent with counselling, Detailed history, preformed Physical examination, Non stress test and Ultrasonography, Modified Bishop's score assessment, Indication for induction, Induction of labour will be done by random selection method with one of the six induction techniques, Progression of labour assessed with cardiac tocograph and partogram, Mode of delivery, Assessment of maternal and foetal outcome was done. The data is expressed as mean and standard deviation for normal distribution or as median and interquartile ranges for non-normal distribution. The incidences of various parameters in the present study were expressed as percentages and chi square analysis was performed for observing the significance of difference among groups. The statistical analysis was performed using SPSS software 11.5 version.

\section{OBSERVATIONS AND RESULTS}

Table 1: Showing the means and SD of Gestational age for induction (weeks).

\begin{tabular}{|c|c|c|}
\hline & Mean & SD \\
\hline $\begin{array}{c}\text { Gestational age for } \\
\text { induction (weeks) }\end{array}$ & 38.96 & 1.19 \\
\hline Modified Bishop's score & 6.35 & 2.26 \\
\hline
\end{tabular}

Table 2: Showing the percentage (\%) of metohds of induction.

\begin{tabular}{|c|c|c|}
\hline Methods of Induction & Number & Percentage (\%) \\
\hline Amniotomy & 30 & 15 \\
\hline Cerviprime & 46 & 23 \\
\hline Foleys & 29 & 14.5 \\
\hline Misoprostol & 30 & 15 \\
\hline Oxytocin & 35 & 17.5 \\
\hline Stripping & 30 & 15 \\
\hline
\end{tabular}


Table 3: Showing the Cardiac Tocograph (\%) of Mode of Delivery after methods of induction.

\begin{tabular}{|c|c|c|c|c|}
\hline \multirow{2}{*}{$\begin{array}{c}\text { Methods of } \\
\text { Induction }\end{array}$} & \multicolumn{2}{|c|}{ Cardiac Tocograph } & \multicolumn{2}{c|}{ Cardiac Tocograph \% } \\
\cline { 2 - 5 } & $\begin{array}{c}\text { normal } \\
\text { vaginal } \\
\text { delivery }\end{array}$ & $\begin{array}{c}\text { Fetal } \\
\text { Distress }\end{array}$ & $\begin{array}{c}\text { normal } \\
\text { vaginal } \\
\text { delivery }\end{array}$ & $\begin{array}{c}\text { Fetal } \\
\text { Distress }\end{array}$ \\
\hline Amniotomy & 10 & 20 & 5 & 10 \\
\hline Cerviprime & 11 & 35 & 5.5 & 17.5 \\
\hline Foleys & 4 & 25 & 2 & 12.5 \\
\hline Misoprostol & 5 & 25 & 2.5 & 12.5 \\
\hline Oxytocin & 5 & 30 & 2.5 & 15 \\
\hline Stripping & 5 & 25 & 2.5 & 12.5 \\
\hline
\end{tabular}

Table 4: Showing the percentage (\%) of Mode of Delivery after methods of induction.

\begin{tabular}{|c|c|c|c|c|}
\hline \multirow{2}{*}{$\begin{array}{c}\text { Methods of } \\
\text { Induction }\end{array}$} & \multicolumn{2}{|c|}{ Mode of Delivery } & \multicolumn{2}{c|}{ Mode of Delivery \% } \\
\cline { 2 - 5 } & Normal & Caesarian & Normal & Caesarian \\
\hline Amniotomy & 10 & 20 & 5 & 10 \\
\hline Cerviprime & 11 & 35 & 5.5 & 17.5 \\
\hline Foleys & 4 & 25 & 2 & 12.5 \\
\hline Misoprostol & 5 & 25 & 2.5 & 12.5 \\
\hline Oxytocin & 5 & 30 & 2.5 & 15 \\
\hline Stripping & 5 & 25 & 2.5 & 12.5 \\
\hline
\end{tabular}

Table 5: Showing the Fetal Outcome Percentage (\%).

\begin{tabular}{|c|c|c|}
\hline Fetal Outcome & Number & Percentage (\%) \\
\hline NICU Admission & 10 & 5 \\
\hline Normal & 190 & 95 \\
\hline
\end{tabular}

\section{DISCUSSION}

During the study period, 200 patients were eligible for inclusion in our study, the mean \pm SD of age this study was $26.06 \pm 3.79$. All were $100 \%$ had hospital delivery. Most of the parturient booked for antenatal care in their third trimester, thus not benefiting from some early pregnancy prophylactic interventions. In our study all were postdated cases only the Mean gestational age in weeks between the 37 and 41 weeks of pregnancy mean \pm SD $38.96 \pm 1$.19, before induction the cervical in ducibility score was determined by Bishop's method. Were in NST reactive and the USG (BPP) was $8 / 8$. Along with this the modified Bhishop's score were mean \pm SD $6.35 \pm 2.26$. Induction of labour was done with various methods: Amniotomy (15\%), Cerviprime (23\%), Foleys (14.5\%), Misoprostol (15\%), Oxytocin $17.5 \%)$, Stripping (15\%). In this the cerviprime is the most commonly used technic for the Induction of labour in our hospital. The induction rate of $11.5 \%$ in Osaheni Lucky
Lawani et al [5] study was much higher than the $6.6 \%$ reported from Maiduguri in Nigeria and an average of $4.4 \%$ (range of $1.4 \%-6.8 \%$ ) reported by Bukola et al. $[6,7]$ but within the $9.9-33.7 \%$ in the United States [8]. The commonest indication for induction of labor which was postdated in $45.8 \%$ is similar to the $46.8 \%$ reported in Maiduguri, Nigeria [5]. Postdate and hypertensive diseases of pregnancy were both reported as the commonest indication in Sokoto by Ekele et al. [9], but this is at variance with the report by Bukola et al. and also Abdul in Zaria which identified prelabor rupture of membranes and hypertension in pregnancy as the commonest indications $[6,10]$.

Accurate determination of gestational age to ascertain a postdate pregnancy may sometimes be an obstetric dilemma due to unsure date of the last menstrual period and nonavailability of early dating ultrasound scan as often the case in resource constrained settings. Other indications for induction in this study were term premature rupture of membranes, intrauterine fetal death, preeclampsia, preterm premature rupture of membranes, eclampsia, intrauterine growth restriction, and gestational diabetes; these indications are similar to those reported in Maiduguri, Zaria, Sokoto, as well as, India, Canada, and the United States $[5,7,11]$.

These indications were mainly for high risk pregnancies that required termination with early induction of labor to prevent perinatal and maternal morbidity and mortality. In such situation, the maternal and fetal risk associated with continuation of the pregnancy should be weighed against the benefits of discontinuation, especially considering the poor health seeking behavior of parturient in south India as well as the lack of modern facilities for fetomaternal surveillance.

We also measured the mode of delivery after the induction. That means whether it is normal vaginal delivery or ceasarian. In that Amniotomy (normal vaginal delivery $5 \%$ and ceasarian $10 \%$ ), Cerviprime (normal vaginal delivery $5.5 \%$ and ceasarian $17.5 \%$ ), Foleys (normal vaginal delivery 2 and ceasarian 12.5\%), Misoprostol (normal vaginal delivery $2.5 \%$ and ceasarian $12.5 \%$ ), Oxytocin (normal vaginal delivery $2.5 \%$ and ceasarian 15\%), Stripping (normal vaginal 
delivery $2.5 \%$ and ceasarian $12.5 \%)$. As per my study the induction of cerviprime increase chances of normal vaginal delivery than other induction.

We also measured the Cardiac Tocograph after the induction. That means whether it is normal vaginal delivery or ceasarian. In that Amniotomy (normal vaginal delivery $5 \%$ and ceasarian $10 \%)$, Cerviprime (normal vaginal delivery $5.5 \%$ and ceasarian $17.5 \%$ ), Foleys (normal vaginal delivery 2 and ceasarian $12.5 \%$ ), Misoprostol (normal vaginal delivery $2.5 \%$ and ceasarian $12.5 \%$ ), Oxytocin (normal vaginal delivery $2.5 \%$ and ceasarian $15 \%$ ), Stripping (normal vaginal delivery $2.5 \%$ and ceasarian $12.5 \%$ ). As per my study the induction of cerviprime increase chances of normal vaginal delivery than other induction. After delivery out of 200 pregnant 200 meternal out were stable. But in case of fetal outcome $5 \%$ of fetal were admitted in the ICU with various complications, they also discharged and started their life with cute little smile.

Labor induction is a method of artificially or prematurely stimulating childbirth in a woman [12]. In some $5-25 \%$ of pregnancies, there comes a time when the fetus and/or mother would be better off if delivery was conducted [13]. The introduction of Cerviprime to clinical practice, particularly their local use for cervical ripening, has decreased major difficulties of labour induction. Duration between induction and delivery has been decreased dramatically by introduction of Cerviprime. Similarly it also decreased associated complication of amnionitis and fetal infection. At term a series of complex biochemical, physiological and physical processes cascade, resulting in delivery. Several events are modulated by neuroendocrine pathways, humoral transmission, steroids and local hormones. During the transition to the onset of labour the cervix becomes soft, short and cervical resistance decreases. This process is called as "cervical ripening". The success of induction depends on the degree of pre-labour changes.

In the non-pregnant state, the cervix consists of around $80 \%$ water and it increases to around $86 \%$ in late pregnancy [14]. Glycosaminoglycans are highly hydrophilic and increase tissue hydration. They thus destabilise the collagen fibrils and. promote ripening. The most abundant glycosaminoglycans in the cervix are chondratin sulphate and its epimer dermatin sulphate $[15,16]$.

The present study thus shows that a single application of intracervical PGE2 gel caused favourable changes in the cervix by increasing the Bishop score and shortened the induction de-livery interval with minimal side effects. To conclude intracervical PGE2 gel application is safe and acceptable method for induction of labour in patients with unfavourable cervix. With the better methods for induction of labour and better techniques of evaluation of fetal wellbeing the rate of induction of labour has further increased. An ongoing search for the better and safer methods for induction will continue in future.

Overall, our systematic research found that Cerviprime is the more effective option for induction of labour and cervical ripening compared with Amniotomy, Foleys, Misoprostol, Oxytocin, Stripping. It also found that higher doses of Cerviprime have no comparative advantages to the lower doses. There is, in general, considerable consistency between trials, except with respect to caesarean section rates and to the low Cerviprime dosage regimens. The rates of caesarean section were inconsistent, tending to be reduced with Cerviprime. The indication for caesarean section was not a prespecified outcome in this study. However, there was a consistent pattern of more operations for fetal distress and fewer for poor labour progress.

No differences in perinatal or maternal outcome were shown. However, the study was not sufficiently large to assess the likelihood of uncommon, serious adverse perinatal and maternal complications. Of particular concern are several reports of uterine rupture following Cerviprime use in women with and without previous caesarean section. The possibility of inadvertent bias because of the unblinded nature of these studies should be kept in mind. In countries in which Cerviprime is being used for non-registered obstetric indications, there is a need for health authorities and professional organisations to clarify the medicolegal 
implications. Particularly in countries in which conventional prostaglandins are unaffordable, health authorities need to decide whether Cerviprime should be used in specific circumstances and, if so, take steps to legalise and regulate such use.

\section{CONCLUSION}

Induction of labour (IOL) needs to be considered when the risk-benefit analysis indicates that delivering the baby is a safer option for the baby, the mother, or both. Our study was to evaluate the outcome of pregnancy at term by elective induction of labour in order to reduce the cesarean section rate. 200 patients were eligible for inclusion in our study, the more effective option for induction of labour and cervical ripening with Amniotomy, Cerviprime, Foleys, Misoprostol, Oxytocin, Stripping. We found that of Cerviprime have comparative advantages to the lower risk of delivery. There is, in general, considerable consistency between trials, except with respect to caesarean section rates. The rates of caesarean section were inconsistent, tending to be reduced with Cerviprime. The indication for caesarean section was not a prespecified outcome in this study. However, Cerviprime can be considered as safe, efficacious, cheap and mother and fetus friendly for the induction of labour.

\section{REFERENCES}

[1]. WHO recommendations for induction of labor. World Health Organization, 2011.

[2]. Mozurkewich E, Chilimigras J, Koepke E, Keeton K, King VJ. Indications for induction of labour: a best evidence review. British Journal of Obstetrics and Gynaecology. 2009 116(5):626-36.

[3]. National Institute for Health and Clinical Excellence. Induction of Labour: NICE Clinical Guideline 70, 2008.

[4]. WHO recommendations for induction of labour 2011 Geneva: World Health Organization 2011.

[5]. Osaheni Lucky Lawani, Azubuike Kanario Onyebuchi, Chukwuemeka Anthony lyoke, Chikezie Nwachukwu Okafo, Leonard Ogbonna Ajah. Obstetric Outcome and Significance of Labour Induction in a Health Resource Poor Setting. Obstetrics and Gynecology International. 2014;5.
[6]. B. G. Bako, J. Y. Obed, and I. Sanusi. Methods of induction of labour at the University of Maiduguri Teaching Hospital, Maiduguri: a 4-year review. Nigerian Journal of Medicine. 2008;17(2):139-42

[7]. Bukola, N. Idi, M. M'Mimunya, W. M. Jean-Jose, M. Kidza, N. Isilda et al., Unmet need for induction of labor in Africa: secondary analysis fromthe 20042005WHO GlobalMaternal and Perinatal Health Survey (A cross-sectional survey). BMC Public Health. 2012;12:722.

[8]. J. L. Tenore. Methods for cervical ripening and induction of labor. American Family Physician. 2003:67(10):2123-8.

[9]. B. A. Ekele, D. C. Nnadi, M. A. Gana, C. E. Shehu, Y. Ahmed, and E. I. Nwobodo. Misoprostol use for cervical ripening and induction of labour in a Nigerian teaching hospital. Nigerian journal of clinical practice. 2007;10(3):234-7.

[10]. M. A.Abdul,U.N. Ibrahim, M.D. Yusuf, and H.Musa. Efficacy and safety of misoprostol in induction of labour in a Nigerian Tertiary Hospital. West African Journal of Medicine. 2007;26(3):213-6.

[11]. F. Witter and L. Devoe. Update on successful induction of labor. Advanced Studies in Medicine, 2005:5(9);888-98.

[12]. Houghton Mifflin Company, The American Heritage Dictionary, 2006.

[13]. Beischer NA, Mackay EV, Colditz PB. Obstetrics and the Newborn, An Illustrated Textbook 1997,3:449.

[14]. Uldbjerg N, Ekman G, Malmstrom A. Ripening of the human uterine cervix related to changes in collagen, glycosaminoglycans and collagenolytic activity. Am J Obstet Gynecol.1983 147:662-6.

[15]. Von Maillot K, Stunhlsatz HW, Mohanaradha krishnan V. Changes in glycosominoglycan distribution in the human uterine cervix during pregnancy and labour. Am J Obstet Gynecol. 1979 135:503-6.

[16]. Ulmstein, Wingerup L, Anderson. Comparison of Prostaglandin E2 gel and intravenous oxytocin for induction of labour. Obstet Gynecol.1979 54:5814.

How to cite this article: Anita Ramesh Annaldasula. ANALYSIS OF MODE OF DELIVERY WITH VARIOUS INDUCTION TECHNIQUES IN TERTIARY CARE HOSPITAL AT RAYALASEMA REGION. Int J Intg Med Sci 2018;5(1):565-569. DOI: 10.16965/ijims.2017.123 